\title{
Série histórica (1997-2012) das condições de oxigenação do rio Capivari (RS) e suas influências sobre a proteção dă vidă aquática do recurso hídrico
}

Historical series (1997-2012) of the oxygenation conditions Capivari (RS) river and its influences on the protection of aquatic life of the water resource

\author{
Victor Rodrigues Aragão
}

Universidade Federal de Santa Maria. Santa Maria., RS, Brasil.

\begin{abstract}
Resumo
Objetivou-se, a partir deste trabalho, analisar as condições de oxigenação do rio Capivari, do ano de 1997 ao de 2012, e suas influências sobre a vida aquática do mesmo. Para sua idealização, foram aplicadas, aos dados coletados, metodologias de natureza quali-quantitativa aliadas às propriedades preferenciais da pesquisa de caráter documental, além de classificações oriundas do próprio autor, quanto às condições de vida aquática em corpos d'água lóticos. As amostragens foram realizadas na estação de monitoramento da qualidade da água do município de Capivari do Sul, da Fundação Estadual de Proteção Ambiental, a uma profundidade fixa de 0,2 m. Através deste estudo foi possível concluir que $92,2 \%$ da vida aquática do rio Capivari foi preservada em função de oxigênio dissolvido durante os dezesseis anos envolvidos no estudo. Foram constatadas degradações da vida aquática no corpo d'água no verão dos anos de 2001, 2005 e 2012, e no outono nos anos de 2002 e 2007. Os baixos índices de oxigênio dissolvido encontrados nesses períodos são explicados, mormente, pelos aumentos de temperatura da água, altas taxas de degradação de matéria orgânica e pela presença de processos que envolveram a nitrificação. Sendo possivel concluir que, de 1997 a 2012, o rio Capivari, nas proximidades do município de Capivari do Sul, apresentou, no geral, boa qualidade de oxigenação e preservação da vida aquática em função desse parâmetro.
\end{abstract}

Palavras-chave: Influências, Oxigênio dissolvido, Degradações, Vida aquática.

\begin{abstract}
The aim of this study was to analyze the conditions of oxygenation of the river Capivari the year 1997 to 2012 and their influences on the aquatic life of that. Methodologies of qualitative and quantitative nature allied to the preferred search properties of documents, were applied in addition to ratings derived from the author himself, as conditions for aquatic life in lotic water bodies. Sampling was conducted on the water quality of the county Capivary South, the Fundação Estadual de Proteção Ambiental, a fixed depth of $0.2 \mathrm{~m}$ monitoring station. Through this study it was concluded that $92.2 \%$ of aquatic life Capivari River has been preserved as a function of dissolved oxygen during the sixteen years engaged in the study. Degradations of aquatic life were found on the body of water in the summer of the years 2001, 2005 and 2012 and fall in 2002 and 2007. Low levels of dissolved oxygen found in these periods are explained, mainly, by the increase of water temperature, high rates of degradation of organic matter and the presence of processes involving nitrification. As can be concluded that from 1997 to 2012, the river Capivari nearby municipality Capivary do Sul, showed in general good quality of oxygenation and preservation of aquatic life due to the oxygenation parameter.
\end{abstract}

Keywords: Influences, Dissolved oxygen, Degradations, Aquatic life. 


\section{Introdução}

Ao longo dos anos, as águas naturais têm perdido, aflitivamente, suas propriedades congênitas, sobretudo, em função das ações antropogênicas. Manifestamente, o desenvolvimento populacional e os crescimentos relativos à economia e à tecnologia ocasionam alterações aos ambientes onde se fazem presentes, entrementes, esses desenvolvimentos, mesmo alterando condições iniciais de um ambiente natural, devem estar em acordo com as resoluções federais e estaduais correspondentes, não ocasionando, particularmente, a exiguidade de corpos d'água (IGAM, 2010).

As dessemelhantes formas de vida, sendo aquáticas ou territoriais, de acordo com FREITAS et al. (2002), dependem fundamentalmente da água, na qual se deve aduzir condições quali-quantitativas preferenciais; essas se baseiam segundo a FEEMA (2009), em um conjunto de propriedades físico-químicas e biológicas que a mesma apresenta em relação à sua aplicação prática. Os padrões de classificação estão abrangidos em potabilidade, estabilidade de condição de risco ao ser humano e na circunstância de preservação dos ecossistemas.

Um dos aspectos de grande importância, ao se analisar a qualidade da água, é a medição do oxigênio dissolvido existente nela. Ao determinarmos qual a quantidade de oxigênio dissolvido na água poderemos avaliar as condições em que se encontra e detectar os impactos ambientais que ela apresenta, além de indicar a capacidade de um corpo d'água natural manter a vida aquática. Ele origina-se de duas fontes: do oxigênio da atmosfera, dissolvido diretamente, e no oxigênio que provém da fotossíntese de plantas aquáticas (SPLABOR, 2010, p.1).

Ainda de acordo com SPLABOR (2010), os fatores que podem ocasionar alterações nas proporções de oxigênio dissolvido (OD) de um recurso hídrico são: temperatura da água, altitude, matéria orgânica em degradação, profundidade, proporção de nutrientes, velocidade e caráter relativo à vazante, quantidade de vegetação natural, mormente, a presença de substâncias tóxicas ou organismos estranhos àquele ambiente.

Além de ser um fator relevante ao equilíbrio de sistemas aquáticos, o OD também atua na manutenção de processos de autodepuração de ambientes lênticos e lóticos (CESTESB, 2013); podendo ter suas condições aduzidas através de Medidor de Oxigênio Dissolvido, e ser manuseado "[...] em tratamento de água e esgoto, laboratórios, mineração, aquários e controle de qualidade" (SPLABOR, 2010, p.1).

O desenvolvimento de uma série histórica envolvendo um recurso hídrico proporciona, à sociedade em geral e acadêmica, a compreensão de uma maneira ampla, e ao mesmo tempo simplificada, sobre as condições de qualidade de um determinado corpo d'água em um vasto período de tempo, bem como na compreensão de problemas ambientais e, até mesmo, sociais que estiveram envolvidos com o mesmo. Dessa forma, com o presente trabalho, objetivou-se avaliar os níveis de OD que se fizeram presentes de 1997 a 2012, no rio Capivari (RS), levando em consideração fatores de alteração e suas influências sobre a vida aquática desse recurso hídrico.

\section{Metodologia}

O rio Capivari está localizado no litoral médio do Rio Grande do Sul, nas proximidades do município de Capivari do Sul, de coordenada de latitude $\left(-30^{\circ}\right.$

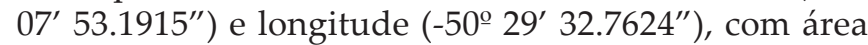
de 417,609 km² e altitude de 12 m; o corpo d'água está inserido na Bacia Hidrográfica do Litoral Médio (L20), como mostra a Figura 1; e o monitoramento deste recurso hídrico está sob responsabilidade da FEPAM - Fundação Estadual de Proteção Ambiental (RS), através da estação de monitoramento da qualidade da água superficial CAP-0115 (FEPAM, 2014).

O município envolvido no estudo recebe número de identificação pela FEPAM (2014), designado por 4304671; está inserido na mesorregião metropolitana de Porto Alegre e microrregião de Osório, com municípios limítrofes: Palmares do Sul, ao sul; Osório, à nordeste; Balneário Pinhal, à leste; Viamão, ao oeste; Santo Antônio da Patrulha, ao norte. E está a uma distância de $63 \mathrm{~km}$ da capital, Porto Alegre.

A região tem clima classificado por subtropical úmido, com ausência de estação seca e presença de temperatura média anual de $16,5^{\circ} \mathrm{C}$. Os meses de setembro a março compõem o espaço de tempo de menor frio (ECO VIAGEM, 2014).

Este estudo foi promovido através de uma pesquisa documental que, segundo Gil (2002, p.48), faz referência à compreensão e tratamento de dados documentais. As informações coletadas são oriundas de relatórios oficiais disponibilizados pela FEPAM.

Foram utilizadas metodologias quali-quantitativas, aliadas às características preferenciais da pesquisa documental, o que proporcionou atingir o objetivo do estudo. Santos (1999, p.46) afirma que os estudos de cunho qualitativo são focados na "descoberta, identificação, descrição aprofundada e na geração de explicações." Quando se trata de pesquisas quantitativas, as mesmas proporcionam a utilização de padrões estatísticos e extensão das contingências aduzidas pela realidade proposta.

Foram aplicadas técnicas de análise multivariada para [...] melhor caracterizar os corpos hídricos da região. As coletas são realizadas pelo serviço de amostragem da FEPAM, seguindo normas adotadas pela CETESB (1987). A preservação e os métodos analíticos seguem os procedimentos definidos pelo Standard Methods (FEPAM, 2014, p.1). 


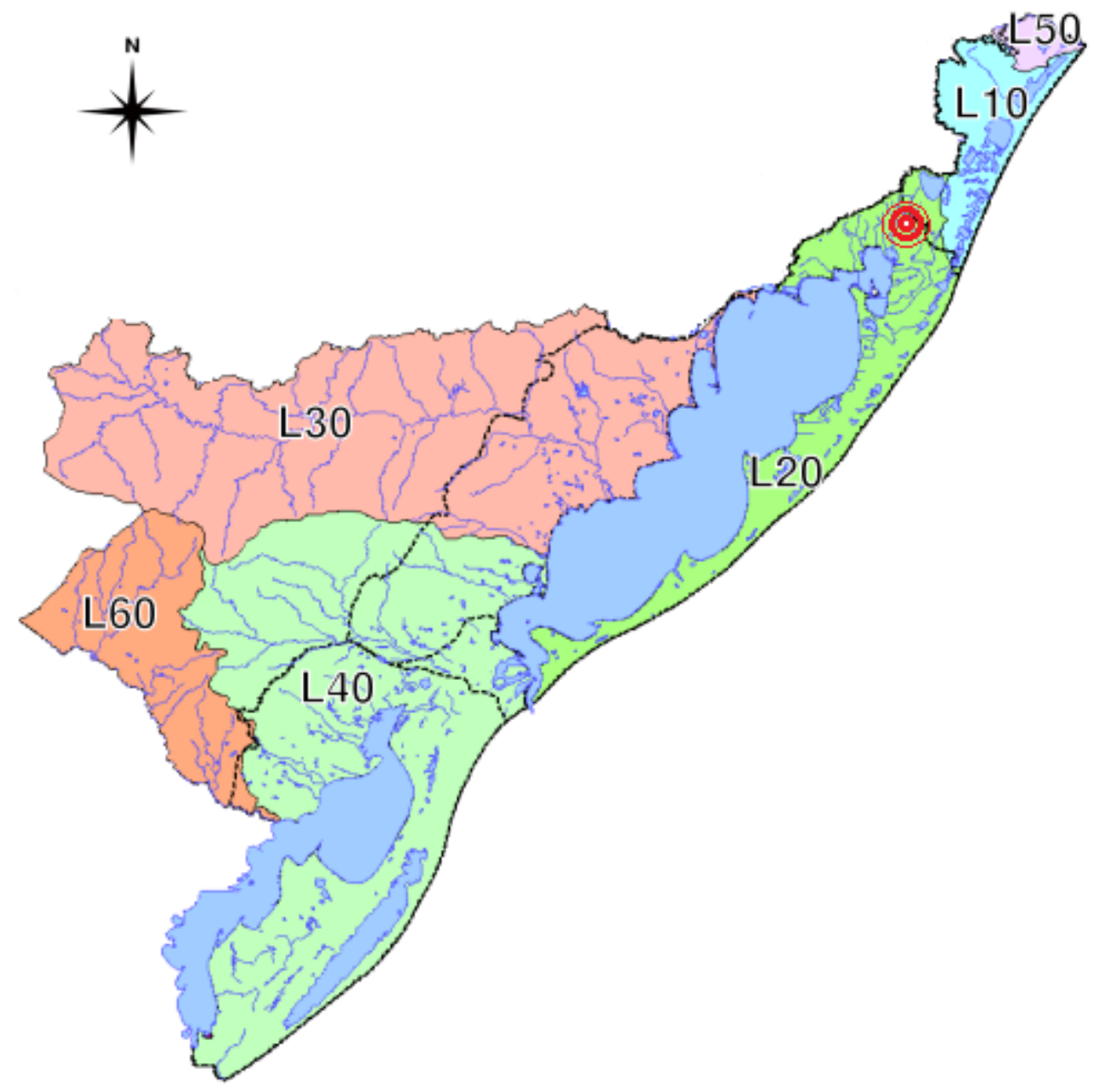

Figura 1. Local do corpo d'água (Adaptado de FEPAM, 2006).

Todas as amostragens, desde 1997 a 2012, foram coletadas a 0,2 $\mathrm{m}$ de profundidade, aproximadamente sobre a ponte na RS-040, onde se faz o acesso ao rio no município de Capivari, do Sul (RS).

Este trabalho teve como objetivo verificar a qualidade de oxigenação do rio Capivari, bem como do nível de proteção da vida aquática do mesmo, através do parâmetro oxigênio dissolvido (OD), a partir da coleta, filtragem e aplicação prática de dados; oriundos da CAP-0115.

\section{Resultados e discussão}

No ano de 1997 ocorreu uma amostragem quanto ao monitoramento da qualidade da água do rio Capivari na CAP-0115, realizada no outono (23/04), na qual foi constatado 5,5 $\mathrm{mg}$ OD/L e fósforo total de 0,134 mg/L, com temperatura da água em $23^{\circ} \mathrm{C}$; a amostragem do ano seguinte, promovida também na estação de outono (01/04), revelou que houve aumento de OD em 1,5 mg/L, apresentando temperatura do recurso hídrico em $17,2^{\circ}$ C; com fósforo total em ambiente lótico de 0,109 mg/L.

A utilização de duas amostragens, no mesmo ano, fez-se presente pela primeira vez em 1999, pela FEPAM, em relação ao rio Capivari, aduzindo uma diferença entre si de 1,4 mg OD/L, sendo o maior valor encontrado na segunda amostragem, realizada no fim do inverno (24/08), de $8 \mathrm{mg}$ OD/L e fósforo total de 0,145 mg/L; a primeira foi realizada no início do outono (26/03) e revelou 6,6 mg OD/L, com fósforo total de 0,151 mg/L (FEPAM, 2014).

Através dos resultados obtidos até 2000 (ano que aduziu através de apenas uma amostragem: $9 \mathrm{mg} \mathrm{OD} / \mathrm{L}$, 0,0962 mg/L de fósforo total e água à 11,1ํㅡ C), foi possível ratificar que, em ocorrências de temperaturas mais baixas, houve maior capacidade do corpo d'água de dissolver oxigênio. Sendo importante ressaltar que a altitude da área de estudo se apresenta em baixa escala, o que evitou que o oxigênio dissolvido apresentasse, até 2000, pouca solubilidade. 
Dessa forma, os anos de 1997 a 2000 estiveram dentro dos padrões recomendados, pela Resolução CONAMA 357/05, em relação à OD; aduzindo menor valor (5,5 mg OD/L), contendo 05 DRP, constatando proteção da vida aquática, não havendo a mortandade de organismos em função do parâmetro de oxigenação; contudo, apresentando CRVA Alta (TABELA 1).

Tabela 1. Classificação da Condição de Risco da Vida Aquática (CRVA) baseada nas taxas de OD acima ou iguais ao limite recomendado pela Resolução CONAMA 357/05.

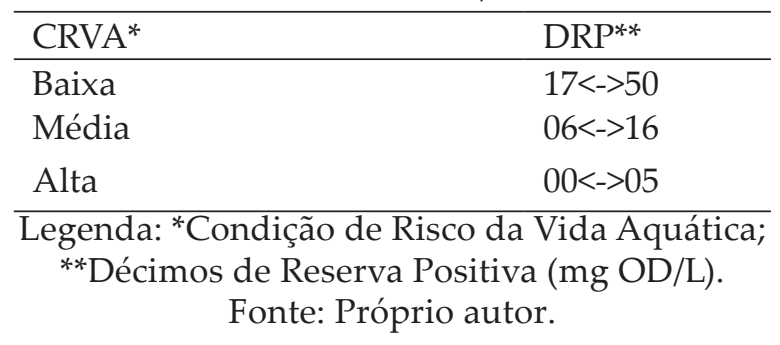

No primeiro ano do século XXI, foram promovidas duas amostragens, a primeira no fim do verão (11/03/01; 4,2 mg OD/L; água à 27으 C e fósforo total de $0,143 \mathrm{mg} / \mathrm{L}$ ) e a segunda no inverno $(27 / 08 / 01 ; 6,5 \mathrm{mg} \mathrm{OD} / \mathrm{L}$; água à $21,3^{\circ} \mathrm{C}$ e fósforo total de $\left.0,124 \mathrm{mg} / \mathrm{L}\right)$. Em 2002, ocorreram também duas amostragens: no início do outono (22/03; 4,7 mg OD/L; água à $14^{\circ} \mathrm{C}$ e fósforo total de 0,146 $\mathrm{mg} / \mathrm{L})$ e no inverno $\left(18 / 08 ; 5,6 \mathrm{mg} \mathrm{OD} / \mathrm{L}\right.$; água à $21,6^{\circ} \mathrm{C}$ e fósforo total de $0,111 \mathrm{mg} / \mathrm{L})$.

A partir dos dados desses dois anos, foi possível constatar que a queda de temperatura, na amostragem no outono de 2002, não promoveu o aumento de OD livre na água, fato que pode ser explicado pelo aumento dos processos de degradação de matéria orgânica (MO), onde ocorre o aprisionamento do oxigênio "presente na água em suas trocas gasosas, provocando o decréscimo do mesmo no ambiente aquático" (CETESB, 2013, p.1).

Nesses dois anos, o menor valor de DRP foi encontrado na amostragem realizada no inverno de 2002, apresentando 06 DRP, tendo CRVA Alta. Vale ressaltar que se fizeram presentes processos iniciais de degradação da vida aquática nas amostragens do verão de 2001 e do outono de 2002.

Foram realizadas duas amostragens no ano de 2003 na CAP-0115, uma no início do outono (22/03; não havendo medição de OD; com água a 22,7º $\mathrm{C}$ e fósforo total de 0,122 mg/L) e outra no inverno $(04 / 08 ; 6,1 \mathrm{mg}$ $\mathrm{OD} / \mathrm{L}$; água à $19^{\circ} \mathrm{C}$ e fósforo total de 0,0999 mg/L). Em 2004, houve medição de parâmetros apenas no inverno $\left(25 / 07 ; 5,3 \mathrm{mg} \mathrm{OD} / \mathrm{L}\right.$; água à $16^{\circ} \mathrm{C}$ e fósforo total de 0,118 $\mathrm{mg} / \mathrm{L})$; notou-se queda de $08 \mathrm{DRP}$ somada à diminuição de temperatura da amostragem do inverno de 2003 para a do inverno de 2004, fato ocasionado, também, pela presença de processos de degradação de MO.

Com apenas 03 DRP, a amostragem do inverno de 2003 revelou CRVA Alta, diferentemente da do inverno de 2004, apresentando CRVA Média; ambos os anos aduziram proteção da vida aquática de acordo com a Resolução CONAMA 357/05, estando acima do limite de 5,0 mg OD/L.

No ano de 2005 foram realizadas duas amostragens, abrangendo o último dia do verão (19/03; 2,5 mg OD/L; água à $26,5^{\circ} \mathrm{C}$ e fósforo total de $\left.0,171 \mathrm{mg} / \mathrm{L}\right)$ e o inverno $\left(02 / 07 ; 6,4 \mathrm{mg} \mathrm{OD/L}\right.$; água à 22,8 ${ }^{\circ} \mathrm{C}$ e fósforo total de $0,04 \mathrm{mg} / \mathrm{L})$. A amostra do verão indicou que não só o aumento de temperatura e a degradação da MO estiveram relacionados com a pouca oxigenação do corpo d'água, mas também pode ser explicada pelo consumo de OD essencial nos processos que envolveram a nitrificação neste corpo d'água, no período em questão; a conversão de nitrogênio amoniacal a nitrito e este a nitrato.

Esses processos são de grande valia, também, na constatação de lançamentos recentes de esgotos domésticos em recursos hídricos. Constatou-se, então, degradação do recurso hídrico no tempo de realização dessa amostra, aduzindo quase uma condição hipóxia, e na quase mortandade integral dos organismos presentes no sistema.

Em 2006 houve amostragem no verão (03/03; 6,8 mg $\mathrm{OD} / \mathrm{L}$; água à $28,2^{\circ} \mathrm{C}$ e fósforo total de $\left.0,116 \mathrm{mg} / \mathrm{L}\right)$ e no inverno (22/07; $9 \mathrm{mg} \mathrm{OD} / \mathrm{L}$; água à $20,2^{\circ} \mathrm{C}$ e fósforo total de $0,159 \mathrm{mg} / \mathrm{L})$. Já em 2007, a primeira amostra foi coletada no início de outono $(27 / 03 ; 2,9 \mathrm{mg} \mathrm{OD} / \mathrm{L}$; água à $28,5^{\circ}$ e sem medição de fósforo total por agentes físicos interferentes) e a segunda no inverno (16/08; 8,1 mg OD/L; água à $18,3^{\circ} \mathrm{C}$ e também sem medição de fósforo total, por temperatura inadequada interferente).

No ano seguinte, foi realizada apenas uma amostragem, no inverno (16/08/08; 5,9 mg OD/L; água à 20,5은 C e fósforo total de $0,29 \mathrm{mg} / \mathrm{L})$. Vale ser destacado que, no verão de 2006, houve aumento de temperatura e 18 DRP, apresentando-se com CRVA Baixa, fato que pode ser explicado pela não presença de processos envolvendo nitrificação no corpo d'água, além da quase ausência de degradação de $\mathrm{MO}$.

No outono de 2007 houve a quase condição hipóxia, à semelhança da amostragem do verão de 2005, que também pode ser compreendida a partir dos processos envolvendo o nitrogênio amoniacal.

No ano de 2009 foram coletadas amostras no início do outono (26/03; não havendo medição de OD por deficiência de equipamento; com água a $22^{\circ} \mathrm{C}$ e fósforo total de $0,11 \mathrm{mg} / \mathrm{L})$ e no inverno (16/07; 8,9 mg OD/L; água à $13,3^{\circ} \mathrm{C}$ e fósforo total de $\left.0,126 \mathrm{mg} / \mathrm{L}\right)$. Já no décimo ano do século XXI foram realizadas amostras no fim do verão (11/03/10; 6,2 mg OD/L; água à 25,1 ํㅡ C e fósforo total de 0,064 mg/L) e no fim do inverno (16/09/10; não havendo medição de OD por deficiência de equipamento; com água a $17^{\circ} \mathrm{C}$ e fósforo total classificado na categoria $\mathrm{CQ}$ pela FEPAM (2014), estando fora do controle de qualidade).

A baixa temperatura da água, no inverno de 2009, explica a elevada taxa de OD. Todas as amostragens envolvidas nestes dois anos em função de OD estiveram dentro do limite indicado pela Resolução CONAMA 
357/05, havendo a proteção da vida aquática nestes períodos em função de OD, mesmo com o não atendimento ao CQ (Controle de Qualidade) do fim do inverno de 2010, em relação ao fósforo total.

Os anos de 2011 e 2012 tiveram também, cada um, duas amostragens, realizadas em 17/03 e 21/07 e 12/01 e 19/07, respectivamente. A amostra do fim do verão de 2011 aduziu um valor de 6,4 mg OD/L, com medição de fósforo total de $0,21 \mathrm{mg} / \mathrm{L}$ e temperatura da água em $24^{\circ}$ $\mathrm{C}$, ainda no mesmo ano, houve a ocorrência de oxigenação de $8,5 \mathrm{mg} / \mathrm{L}$, fósforo total de $0,176 \mathrm{mg} / \mathrm{L}$ e temperatura do rio em $15^{\circ} \mathrm{C}$ no inverno. A amostragem do verão de 2012 revelou 3,6 mg OD/L, fósforo total de 0,155 mg/L e temperatura da água em $28,8^{\circ} \mathrm{C}$, já a amostra do inverno do mesmo ano aduziu $7,4 \mathrm{mg} / \mathrm{L}$ de oxigenação, fósforo total sem medição por agentes físicos interferentes e uma temperatura da água em $13,4^{\circ} \mathrm{C}$.

Notou-se, mais uma vez, a ocorrência de diminuição de OD de maneira drástica no verão do décimo segundo ano do século XXI, realidade que pode ser compreendida, mais uma vez, pela alta temperatura do recurso hídrico em questão, além da presença de $\mathrm{MO}$, havendo processo inicial de degradação da vida aquática. Todas as outras análises, com exceção desta, estiveram dentro do padrão recomendado, com destaque nestes dois anos ao inverno de 2011, com 35 DRP, apresentando-se com CRVA Baixa.

A simplificação dos resultados foi resumida na Tabela 2, com indicações de cores em verde (com ocorrência de preservação em todo o ano) e em laranja (estação do ano em que houve degradação).

Tabela 2. Condição da vida aquática em função do parâmetro de oxigenação.

\begin{tabular}{ll}
\hline Ano & Condição da vida aquática \\
\hline 2012 & Degradação (no verão) \\
2011 & Preservação integral \\
2010 & Preservação integral \\
2008 & Preservação integral \\
2007 & Preservação integral \\
2006 & Degradação (no outono) \\
2005 & Preservação integral \\
2004 & Degradação (no verão) \\
2003 & Preservação integral \\
2002 & Preservação integral \\
2001 & Degradação (no outono) \\
2000 & Degradação (no verão) \\
1999 & Preservação integral \\
1998 & Preservação integral \\
1997 & Preservação integral \\
\hline
\end{tabular}

Fonte: Próprio autor.

\section{Considerações finais}

Foi possível concluir, com este estudo, que $92,2 \%$ da vida aquática do rio Capivari (RS) foi preservada em função de oxigênio dissolvido, do ano de 1997 ao de 2012. Portanto, o recurso hídrico apresentou águas, no geral, de boa qualidade em relação a este parâmetro, com a maioria das condições de oxigenação acima do padrão recomendado pela Resolução CONAMA 357/05, com poucas variações negativas. Vale ressaltar que o considerável nível de preservação encontrado não excetua o corpo d'água de receber mais pontos de amostragem de monitoramento e novos estudos que proporcionem a maior revitalização do mesmo.

\section{Referências}

CETESB - Companhia Ambiental do Estado de São Paulo. Alterações físico químicas. Disponível em: $<$ http://www.cetesb.sp.gov.br/mortandade/causas oxigenio.php>. Acesso em: 19 de out. 2013.

CONAMA - Conselho Nacional de Meio Ambiente, 2005. Decreto 99274, de 6 de junho de 1990.

Resolução 357, de 17 de março de 2005.

ECO VIAGEM. Lagoa do Peixe (RS): Santuário das aves migratórias. Disponível em: $<\underline{\mathrm{http}}$ :// ecoviagem.uol.com.br/brasil/rio-grande-do-sul/ parque-nacional/lagoa-do-peixe/>. Acesso em: 04 de jan. 2014.

FEEMA - Fundação Estadual de Engenharia do Meio Ambiente. Qualidade da água. Disponível em: $<$ http://www.feema.ri.gov.br/qualidade-agua. asp?cat=75>. Acesso em: 25 de abril 2009.

FEPAM - Fundação Estadual de Proteção Ambiental - RS. Qualidade Ambiental: Região Hidrográfica das Bacias Litorâneas. Disponível em: $<$ http://www. fepam.rs.gov.br/qualidade/monitor agua litoral. asp>. Acesso em: 05 de fev. 2014.

FEPAM - Fundação Estadual de Proteção Ambiental - RS. Região Hidrográfica das Bacias Litorâneas, 2006. Disponível em: $<\underline{\text { http://www.fepam.rs.gov.br/ }}$ qualidade/Imagens/litoral geral.png $>$. Acesso em: 19 de out. 2013.

FREITAS, V. P. S.; BRÍGIDO, B. M.; BADOLATO, M. I. C.; ALABURDA, J. Padrão físico-químico da água de abastecimento público da região de Campinas. Rev. Inst. Adolfo Lutz, 61 (1): 51-58, 2002.

GIL, Antonio Carlos. Como elaborar projetos de pesquisa. $4^{a}$ edição. São Paulo: Atlas, 2002. 
IGAM - Instituto Mineiro de Gestão das Águas.

Monitoramento da qualidade das águas superficiais na Bacia do Rio Jequitinhonha em 2009. Belo Horizonte: Instituto Mineiro de Gestão das Águas, 2010. 154 p.

SANTOS, Antônio Raimundo dos. Metodologia Científica: a construção do conhecimento, Rio de Janeiro, DP\&A editora, 1999.

SPLABOR - Equipamentos para Laboratórios.

Oxigênio Dissolvido na água: um indicador de vida. Disponível em: $<$ http://www.splabor.com. br/blog/noticias/oxigenio-dissolvido-na-agua-umindicador-de-vida/>. Acesso em: 13 de set. de 2010. 